\title{
Factors Influencing Ball Throwing Velocity in Young Female Handball Players
}

\author{
I. Zapartidis ${ }^{*}, 1$, D. Skoufas ${ }^{2}$, I. Vareltzis ${ }^{1}$, T. Christodoulidis ${ }^{3}$, T. Toganidis ${ }^{3}$ and P. Kororos ${ }^{1}$ \\ ${ }^{I}$ Department of Physical Education and Sport Science, National and Kapodistrian University of Athens, Greece \\ ${ }^{2}$ Department of Physical Education and Sport Science, Aristotle University of Thessaloniki, Greece \\ ${ }^{3}$ Department of Physical Education and Sport Science, Democritus University of Thrace, Greece
}

\begin{abstract}
Aim of this study was the investigation of the relationship between throwing ball velocity and specific anthropometric and physical fitness characteristics of young female team handball players $(n=220$, mean \pm SD age $13.99 \pm 1.06$ yrs and playing experience $3.66 \pm 1.66 \mathrm{yrs}$ ). Throwing velocity was assessed with a radar gun while body height, body mass, body mass index, arm span, hand length and spread, standing long jump, 30m sprint, sit and reach flexibility and estimated maximal oxygen uptake were also measured. The results showed that throwing performance is significantly $(\mathrm{p}<0.05)$ correlated with all variables calculated in this study except of the body mass index. This suggests that high performance requires advanced motor abilities and anthropometric features for these ages.
\end{abstract}

Keywords: Team handball, throwing velocity, female adolescent athletes, physical fitness.

\section{INTRODUCTION}

Throwing is considered as one of the most important technical skills in competitive team hand ball as it is a major determinant of all actions taken by the players. For a proper execution of a throw, the achievement of maximal voluntary velocity is necessary, depending on the sort of the throw, whilst accuracy is always a demand $[1,2]$. Those skills should be developed by all players, regardless of the team's role distribution and playing post. Gender and age [2-5], muscular strength and neuromuscular coordination [6,7], ball weight and ball size [8], are reported as factors that influence ball velocity. However, there is still a discussion concerning the influence of anthropometric characteristics $[6,9]$. Bayios [10] reported ball velocity to be positively correlated to body size, upper and lower extremities' length. Skoufas et al. [11] reported significant correlations between ball velocity and hand spread probably because the later contribute to the safe holding of the ball $[8,11]$. Sakurai \& Miyashita [4] studied the development of throwing skill in boys and girls aged 3 to 9 years with respect to upper limb movement. They report sex-related differences in throwing ability between the ages of five and seven years. After the age of 7 years, improvement in performance of the females depended on kinematic characteristics of the upper limbs and muscular power, while in males the same factors needed to be combined with practice. Pauwels [3], investigated the relation of several anthropometric measures and physical skills of 12 to 19 years old non-experienced boys, with ball velocity. It was found that below the age of 16 , strength is the most significant factor determining ball velocity, with body size also being a key factor.

*Address correspondence to this author at the University of Athens, Department of Physical Education \& Sports Science, 41 Ethnikis Antistasis st, 17237, Greece; Tel: +30 210 7276120; Fax: +30 2107276090 ;

E-mail: elzapa@phed.uoa.gr
There is a scarcity of data in the literature concerning the relation between handball specific physical abilities and ball velocity for young subjects [3]. Therefore, the aim of the present study was the examination of the relations between anthropometric variables and physical abilities and ball velocity in young female handball players. It was hypothesized that specific anthropometric and physical fitness characteristics, correlate with ball velocity.

\section{METHODS}

\section{Participants}

For the purpose of the study 220 handball players participated from all over Greece. All participants were female handball players (age 13.99 \pm 1.06 years). Hand spread and $30 \mathrm{~m}$. running speed was measured in 120 participants only. Participants were questioned and none of them reported any previous injury. Both participants and their parents were informed about the procedures of the measurements and provided their written consent for participating according to the research policy of the University of Athens.

\section{Measurements}

\section{Anthropometric Characteristics}

Body height, body mass, body mass index (BMI), arm span, hand spread and length were measured for each subject. All length characteristics were measured to the nearest $0.1 \mathrm{~cm}$ and mass was measured using a precision scale (Bilance Salus, Italy) to the nearest $0.5 \mathrm{~kg}$. All measurements were taken by the same investigator. The body height was measured at standing position with the shoulders and heels adjacent to a wall using a height meter (220 Seca, Germany). Arm span was measured from the right to the left middle finger tip with the arms extended and abducted. Hand spread was measured from the fingertip of the thump to the fingertip of the fifth finger with all fingers abducted. Hand length was considered as the distance from mid-stylion to dactylion. 
BMI was computed as the ratio of body mass to the squared standing stature $\left(\mathrm{kg} \cdot \mathrm{m}^{-2}\right)$. All players reported their experience in years of training.

\section{Physical Fitness Characteristics}

Five variables were recorded for each player. These included aerobic capacity, explosive power of the lower limbs, throwing velocity, flexibility and running speed.

Concerning aerobic capacity, maximal oxygen uptake $\left(\mathrm{VO}_{2 \max }\right)$ was estimated using a regression equation with input parameters the age and performance of the last stage of a 20-m shuttle run test. Participants ran in small groups back and forth along a $20 \mathrm{~m}$ course, following a sound signal from a prerecorded cd. Running speed was increased by $0.5 \mathrm{~km} \mathrm{~h}^{-1}$ each minute from a starting speed of $8.5 \mathrm{~km} \mathrm{~h}^{-1}$. The test stopped when the participants were no longer able to follow the set pace [12]. The participants were instructed and encouraged to complete as many stages as possible.

Standing long jump was used for assessing the explosive power of the lower limbs by instructing players to stand behind a line and jump as far as possible - allowing arms and legs countermovement.

Ball velocity was measured with a radar gun (Sports Radar 3300, Sports Electronics Inc.), with an accuracy of \pm 0.1 $\mathrm{km} / \mathrm{h}$ within a field of $10^{\circ}$, as defined by the manufacturer. The height of the gun radar was adjusted to each athlete's throwing arm height, at a perpendicular position towards the throwing arm. The contra-lateral leg of the throwing arm was placed to the front and was steadily on the ground (penalty throw).

Lower back and hamstrings flexibility was measured with the sit and reach test to the nearest $\mathrm{cm}$. Players were instructed to sit with their knees extended and to perform a maximal trunk flexion, aiming to reach as far forward as possible. A $90^{\circ}$ angle was kept for ankles, while value " 0 " was set at the position of just reaching the toes.

Running speed test included a $30-\mathrm{m}$ sprint from a standing position. Times were recorded using electronic photocells (Brower timing system, USA). The players had to run for a distance of $30 \mathrm{~m}$ as fast as they could.

Except 20-m shuttle run test, all other tests were performed twice and the best performance was selected for analysis. Prior to the evaluation all participants performed a 15-min warm up, in order to prevent any potential injuries and to maximize the performance. The warm up included jogging and stretching of the upper and lower limbs.

\section{Statistics}

Distribution normality was proved with the KolmogorovSmirnov test. All variables were normally distributed and therefore parametric statistics were applied. Statistics included the calculation of Pearson correlation coefficients (level of significance $\mathrm{p}<0.05$ ), as well as descriptive statistics (Mean, SD). Data were analyzed using the SPSS 11.5 statistics package for windows.

\section{RESULTS}

Physical fitness and anthropometric characteristics of the sample are shown in Table 1. Throwing ball velocity ranged from 42 to $74 \mathrm{~km} / \mathrm{h}(\mathrm{M}=56.77, \mathrm{SD}=6.76)$. Table 2 shows results of Pearson coefficients of correlation between throwing velocity and anthropometric and physical fitness parameters. Ball velocity was found to be significantly related to playing experience $(p<0.001)$, body height $(p<0.001)$, body weight $(p=0.001)$, hand length $(p<0.001)$, hand spread $(p<0.001)$, and arm span $(p<0.001)$. No relationship was found between ball velocity and BMI $(p>0.409)$. As for the physical abilities, ball velocity was found to be correlated to standing long jump $(p<0.001)$, flexibility $(p<0.001), 30$ meters sprint running $(p<0.001)$ and estimated maximal oxygen uptake $(p=0.030)$.

Table 1. Anthropometric and Physical Characteristics of the Sample

\begin{tabular}{|c|c|c|c|c|}
\hline Variables & Mean & SD & Max & Min \\
\hline Body Height (cm) & 163.50 & 6.40 & 181.00 & 149.00 \\
\hline Body Mass (kg) & 58.61 & 8.64 & 88.40 & 40.20 \\
\hline BMI $\left(\mathrm{kg} \cdot \mathrm{m}^{-2}\right)$ & 21.89 & 2.71 & 31.41 & 16.47 \\
\hline Hand Length $(\mathrm{cm})$ & 17.82 & 0.80 & 20.00 & 16.10 \\
\hline Hand Spread $(\mathrm{cm})$ & 20.89 & 1.17 & 23.80 & 17.80 \\
\hline Arm Span (cm) & 166.46 & 7.46 & 189.00 & 149.30 \\
\hline Standing Long Jump (cm) & 175.19 & 20.84 & 228.00 & 108.50 \\
\hline 30-m Sprint (sec) & 5.16 & 0.25 & 5.78 & 4.63 \\
\hline Sit and Reach $(\mathrm{cm})$ & 34.08 & 7.30 & 52.00 & 18.00 \\
\hline $\mathrm{VO}_{2} \max \left(\mathrm{ml} \cdot \mathrm{kg}^{-1} \cdot \mathrm{min}^{-1}\right)$ & 46.41 & 4.62 & 56.20 & 34.33 \\
\hline Playing Experience (yrs) & 3.55 & 1.66 & 8.00 & 1.00 \\
\hline
\end{tabular}

Table 2. Results of Pearson Coefficients of Correlation Between Throwing Velocity and Anthropometric and Physical Fitness Parameters

\begin{tabular}{|c|c|c|c|}
\hline \multirow{2}{*}{ Variables } & \multicolumn{3}{|c|}{ Statistics } \\
\cline { 2 - 4 } & $\mathbf{n}$ & $\mathbf{p}$ & $\mathbf{p}$ \\
\hline \hline Body Height & 220 & 0.335 & $<0.001$ \\
\hline Body Mass & 220 & 0.231 & 0.001 \\
\hline BMI & 220 & 0.064 & 0.409 \\
\hline Hand Length & 220 & 0.288 & $<0.001$ \\
\hline Hand Spread & 120 & 0.368 & $<0.001$ \\
\hline Arm Span & 220 & 0.340 & $<0.001$ \\
\hline Standing Long Jump & 220 & 0.321 & $<0.001$ \\
\hline 30 -m Sprint & 120 & -0.243 & 0.009 \\
\hline Sit and Reach & 220 & 0.237 & $<0.001$ \\
\hline VO ${ }_{2}$ max (estimated) & 200 & 0.155 & 0.030 \\
\hline Playing experience & 220 & 0.363 & $<0.001$ \\
\hline
\end{tabular}

$\mathrm{n}=$ sample size, $\mathrm{r}=$ coefficient of correlation; significance level $\mathrm{p}<0.05$.

\section{DISCUSSION}

In the present study, main finding is the increased correlation of throwing velocity to hand spread and arm span, 


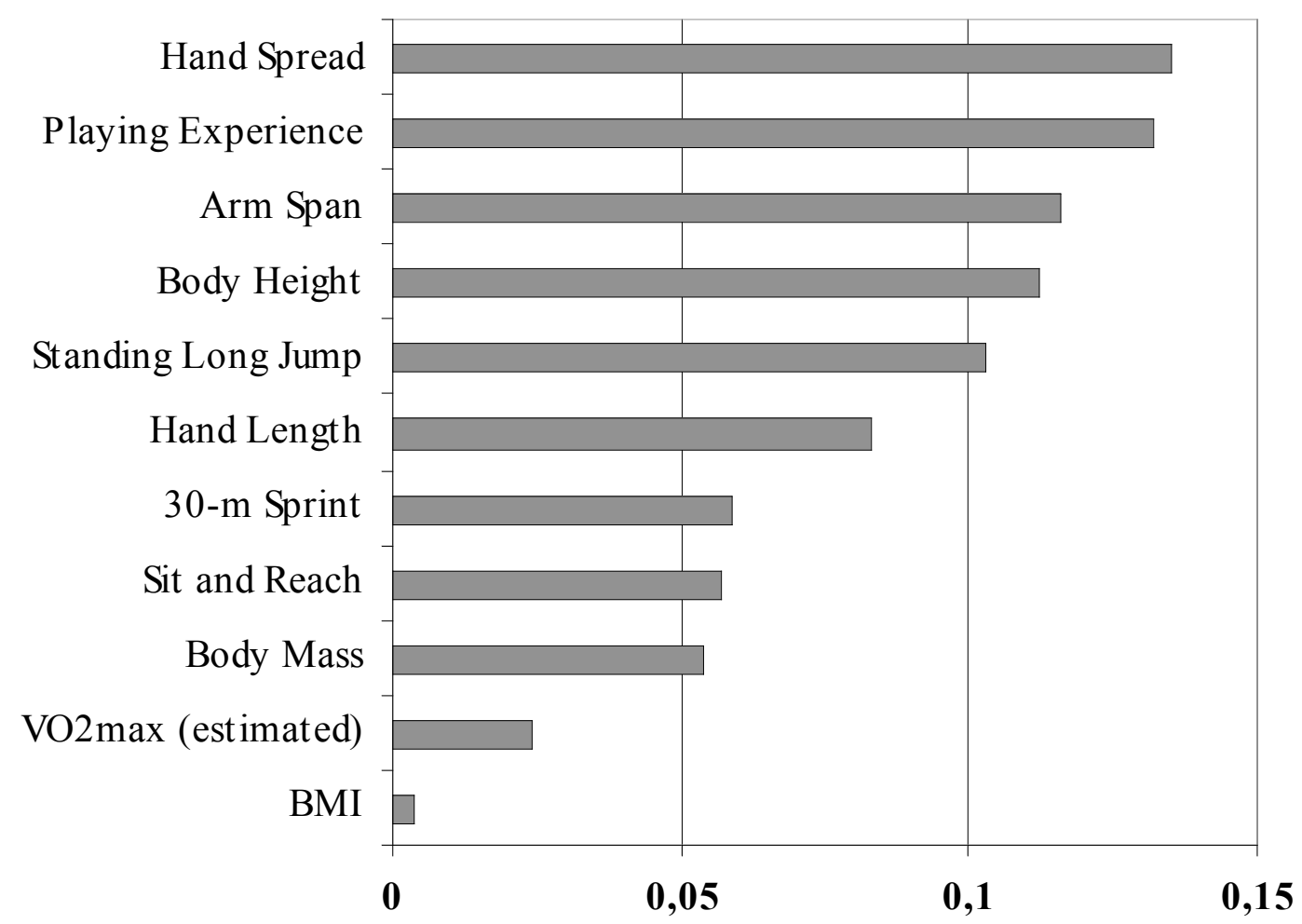

Fig. (1). Graphical representation of $\mathrm{r}^{2}$ values in descending order for all anthropometric and physical fitness parameters.

compared to the other anthropometric characteristics (Fig. 1). Out of the motor abilities, muscular power of the lower limbs as evaluated in standing long jump shows the higher correlation with ball velocity. This suggests the importance of the lower limbs in the kinematic chain.

\section{Anthropometric Characteristics}

Body height and arm span are positively correlated to the throwing ball velocity. It is generally accepted that body height is positively affecting all body dimensions [2]. This positive correlation of the height to the ball velocity is in accordance with previous studies involving male and female athletes $[2,10]$, although there are also conflicting results $[6$, $9,11]$. A Strong positive correlation between ball velocity and arm span is reported by Skoufas et al. [11]. Pauwels [3] report that there is a positive correlation between ball velocity and segmental body length measurements in boys aged 14-16 years, while similar correlations were not evident in subjects aged 16-19 years. According to studies, when an athlete has increased segmental body length measurements, he/she can throw the ball with higher velocity. The combination of a longer humerus and a higher angular velocity results in higher linear ball velocity $[5,13,14]$. Mechanically, an increase of a rotation radius should cause a proportional increase of the force applied to the ball, and consequently an increase of the ball's linear velocity. During an overarm throw, the movement's rotation axis is consisted from the arm's longitudinal axis [15]. Reasonably, an overall longer limb has a positive effect on ball release velocity. Opposing to these results, the study of Jöris et al. [6] did not find any correlation between ball velocity and segmental body lengths. They claim that athletes with short segmental body measurements are capable to reach high throwing performance levels as a result of a more efficient energy transition.
The notably positive correlation of the throwing ball velocity with the hand span distance (spread) and the hand length confirms the importance of these parameters to handball. These results are in accordance with previous studies in handball $[3,4,11]$ and water polo [16]. Increased length and hand spread are important for a stable ball grip and accordingly for a proper throwing technique [8]. It is believed that the stable ball grip allows the athlete to maximally accelerate the ball during the whole throwing movement [11]. The present study, in consistence with previous research found a strong positive correlation between ball release velocity and body mass $[2,11]$. Recently, it was found that ball velocity during spiking in volleyball has a tendency for a positive correlation with body mass $(p=0.055)$, while it correlates with BMI $(p=0.040)$ in volleyball players aged 26 years [17]. Conversely, earlier researchers did not report such correlation between body mass or BMI and ball velocity, concerning male baseball athletes [18], female volleyball athletes [9], and female handball athletes [6]. The correlation between ball throwing velocity and body mass in the present study could be possibly attributed to a potential linear relationship of body mass and muscular mass.

\section{Physical Fitness Characteristics}

Running speed and explosive power are important prerequisite factors in competitive handball $[19,20]$. The power of the lower extremity and the maximal running speed, as expressed by standing long jump and 30-meter speed, respectively, had a significant correlation with ball throwing velocity. The former association has been also reported in high level handball male and female players [20]. Our data are also in accordance with a study of volleyball players which reports a significant correlation between vertical jump and ball velocity during spiking [17] and with another study 
which reported a correlation between squat jump performance and medicine ball throwing velocity [21]. Most researchers agree that explosive lower limb power may be highly associated with throwing ball velocity $[6,22-24]$. This is supported by the fact that the main factor affecting ball velocity is the effective energy transition from ground to the lower extremities and through the kinematic chain to the throwing upper limb $[6,23]$. The correlation of running speed with ball throwing velocity indicates that as long as the ability of attaining maximal speed increases, the ball throwing velocity also increases. In the literature there are no reports to aid to a comparison of our results to relevant studies. This correlation may be attributed to the type of the muscle fibers [25]. In high velocity movements like throwing, fast motor units are preferentially recruited [26, 27]. It is demonstrated that in power athletes (sprinters, throwers, jumpers and weight lifters) the size of the glycolytic fibers (IIx type), is approximately the triplicate of the oxidative glycolytic fibers (IIa type), despite the fact that the overall distribution of the slow and fast twitch fibers is proportional in the muscles of the lower and upper extremity [28]. Since stabilization of this distribution occurs in very early age [29] and the activation is frequent in sports like handball $[26,30]$, it is possible that the combination of these two factors accounts for the association between activities with high demands on strength and velocity.

In the present study, estimated aerobic capacity correlates with ball throwing velocity. The absence of any relevant reports impedes the comparison of this finding. However, in a previous study, when the maximal oxygen consumption was expressed in absolute values $(1 / \mathrm{min})$, a high association with medicine ball throwing was shown, while when normalized to body mass $\left(\mathrm{ml} \cdot \mathrm{kg}^{-1} \cdot \mathrm{min}^{-1}\right)$, the correlation was less evident [31]. In football, maximal ball velocity during kicking does not seem to be negatively affected by the improvement in the player aerobic capacity after a training protocol [32]. The greater improvement in aerobic capacity is noted between 11-15 years of age [33] and in this age frame, children are usually characterized by a general capacity. Accordingly, a child with high aerobic capacity is likely to have high anaerobic capacity as well [34]. Handball training combines medium intensity endurance exercises and high intensity intermittent exercises with many throws. This possibly improves equally aerobic, anaerobic capacity and power [35]. In addition, it is reported that this sport requires special characteristics like production of explosive power from the lower and upper extremities, as well as the ability of aerobic energy production [36].

Flexibility, as it was measured by the sit and reach test, seems to affect throwing velocity at these ages. An earlier study [3] reported a weak correlation between ball velocity and flexibility. However, female handball players who participated in this study were far more familiar with overarm throwing technique, than the non-experienced schoolchildren participants of Pauwels' study [3], who used their personal specific motor qualities in order to overcome technical weaknesses. According to Hong et al. [7], the elements of torso flexibility and motor control, which are lacking from non-experienced throwers, can considerably affect throwing performance.
In the present study it was found that playing experience influences ball throwing velocity at these ages. Players who trained more, managed to achieve higher ball velocities, and at the same time they probably improved their muscular coordination, which was directed to their upper extremities reflecting in improved throwing performance [3, 37]. In water polo it was also reported, that senior female player with 9.8 years of experience demonstrated a significantly higher throwing velocity than junior female elite players with 6.4 years of experience [16]. Freeston and colleagues [38], do not report any training experience effects on ball velocity between elite senior females and elite under-19 years females cricket players. However, he suggested that training experience as well as training volume played a potential role, because they seemed to affect peak and mean maximal throwing velocity.

\section{CONCLUSION}

The aim of the present study was the examination of the relations between anthropometric variables and physical abilities and ball velocity in young female handball players. Fitness, as expressed through these specific tests, combined with training experience and anthropometric characteristics such as hand spread and arm span, seem to be the main factor correlating with ball velocity in 14-year old female handball players. Trainers should take into account these characteristics during handball talent selection, because they tend to be a requirement for future high level performance.

\section{REFERENCES}

[1] Zapartidis I, Gouvali M, Bayios I, Boudolos K. Throwing effectiveness and rotational strength of the shoulder in team handball. J Sports Med Phys Fitness 2007; 47: 169-78.

[2] Van Den Tillar R, Ettema G. Effect of body size and genter in overarm throwing performance. Eur J Appl Physiol 2004; 91: 4138.

[3] Pawels J. The relationship between somatic development and motor ability, and throwing velocity in handball for secondary school students. Biomechanics of Sports and Kinanthropometry. University of Leuven, Symposia Specialist Inc 1976; pp. 357-69.

[4] Sakurai M, Miyashita M. Development aspects of overarm throwing related to age and sex. Hum Movement Sci 1983; 2: 67-76.

[5] Fleising G, Barrentine S, Zheng N, Escamilla R, Andrews J. Kinematic and kinetic comparison of baseball pitching among various level of development. J Biomech 1999; 32: 1371-5.

[6] Jöris H, van Muyen E, van Ingen SG, Kemper H. Force, velocity and energy flow during the overarm throw in female handball players. J Biomech 1985; 18: 409-14.

[7] Hong DA, Cheung TK, Roberts EM. A three-dimensional, sixsegment chain analysis of forceful overarm throwing. J Electromyogr Kinesiol 2001; 11: 95-112.

[8] Burton AW, Greer NL, Wiese DM. Variation in grasping and throwing patterns as a function of ball size. Pediatr Exerc Sci 1993; 5: $25-41$.

[9] Ferris DP, Signorile JF, Caruso JF. The relationship between physical and physiological variables and volleyball spiking velocity. J Strength Cond Res 1995; 9: 32-6.

[10] Bayios I. Factors influence accuracy and throwing velocity in team handball. Ph.D. diss., Dept of Physical Education and Sports Science, National and Kapodistrian University of Athens, Greece 1998.

[11] Skoufas D, Kotzamanidis C, Hatzikotoylas K, Bebetsos, G, Patikas D. The relationship between the anthropometric variables and the throwing performance in handball. J Hum Movement Stud 2003; 45: 469-84.

[12] Léger L, Mercier D, Gadoury C, Lambert J. The multistage 20 metre shuttle run test for aerobic fitness. J Sports Sci 1988; 6: 93101. 
[13] Miyashita M, Tsunoda T, Sakurai S, Nishizono H, Mizuno T. Muscular activities in the tennis serve and overhead throwing. Scand J Sports Sci 1980; 2: 52-8.

[14] Bowne M. Relationship of selected measures of acting body levers to ball throwing velocities. Res Qua 1960; 31: 392-402.

[15] Winter D. Biomechanics and motor control of human movement. $2^{\text {nd }}$ ed. New York: John Wiley \& Sons, Inc 1990.

[16] Varamenti E, Platanou T. Comparison of anthropometrical, physiological and technical characteristics of elite senior and junior water polo players: a pilot study. Open Sports Med J 2008; 2: 50-5.

[17] Forthomme B, Croisier, J, Ciccarone G, Crielaard J, Cloes M. Factors correlated with volleyball spike velocity. Am J Sports Med 2005; 33: 1513-9.

[18] Hooks G. Prediction of baseball ability through an analysis of measurement of strength and structure. Res Q Exerc Sport 1959; 30: $38-43$.

[19] Ohnjec K, Vuleta D, Milanović, D, Gruić I. Performance indicators of teams at the 2003 world handball championship for women in Croatia. Kinesiology 2008; 40: 69-79.

[20] Granados C, Izquierdo M, Ibañez J, Bonnabau H, Gorostiaga EM. Differences in physical fitness and throwing velocity among elite and amateur female handball players. Int J Sports Med 2007; 28: 860-7.

[21] Ikeda Y, Kijima K, Kawabata K, Fuchimoto T, Ito A. Relationship between side medicine ball throw performance and physical ability for male and female athletes. Eur J Appl Physiol 2007; 99: 47-55.

[22] Marques M, González-Badillo J. In- season resistance training and detraining in professional team handball players. J Strength Cond Res 2006 ; 20: 563-71.

[23] Bayios I, Anastasopoulou E, Sioudris D, Boudolos K. Relationship between isokinetic strength of the internal and external shoulder rotators and ball velocity in team handball. J Sports Med Phys Fitness 2001; 41: 229-35.

[24] Fleck S, Smith S, Craid M, Denabam T, Snow R, Mitchel M. Upper extremity isokinetic torque and throwing velocity in team handball. J Appl Sport Sci Res 1992; 6: 120-4.

[25] Faulkner J, Claflin D, McCully K. Power output of fast and slow fibers from human skeletal muscles. Champaign, Illinois: Human Kinetics Publishers, Inc1986.
[26] McArdle W, Katch F, Katch V. Essentials of exercise physiology. $2^{\text {nd }}$ ed. Maryland: Lippincott Williams \& Williams 2000.

[27] Hoff J, Almåsbakk B. The effects of maximum strength training on throwing velocity and muscle strength in female team handball players. J Strength Cond Res 1995; 9: 255-8.

[28] Bergh U, Thorstensson A, Sjôdin B, Helten B, Piehl K, Karlsson J. Maximal oxygen uptake and muscle fiber types in trained and untrained humans. Med Sci Sports 1978; 10: 151-4.

[29] MacDougall J, Bell R, Howald H. Skeletal muscle ultra structure and fiber types in prepubescent children. In: Nagle F, Montoye $\mathrm{H}$, Eds. Exercise in Health and Disease. Charles C. Thomas, Springfield 1982; p. 113.

[30] Gorostiaga E, Granados M, Ibáñez J, Izquierdo M. Differences in physical fitness and throwing velocity among elite and amateur male handball players. Int J Sports Med 2004; 25: 1-8.

[31] Drake V, Jones G, Brown J, Shephard R. Fitness performance tests ant their relationship to the maximal oxygen uptake of adults. Canad Med Ass J 1968; 99: 844-8.

[32] Helgerud J, Engen L, Wisløff U, Hoff J. Aerobic endurance training improves soccer performance. Med Sci Sports Exerc 2001; 33: 1925-31.

[33] Pearson D, Naughton G, Torode M. Predictability of physiological testing and the role of maturation in talent identification for adolescent team sports. J Sci Med Sport 2006; 9: 277-87.

[34] Mayers N, Gutin S. Physiological characteristics of elite prepubertal cross - country runners. Med Sci Sports 1979; 11: 172-6.

[35] Izumi T, Kouji N, Motoki K, et al. Effects of moderate-intensity endurance and high-intensity intermittent training on anaerobic capacity and $\mathrm{VO}_{2}$ max. Med Sci Sports Exerc 1996; 28: 1327-30.

[36] Wit A, Eliasz J, Janiak J, Wit B, Viitasalo J. Modifications de la puiisance du train inférieur des handballeurs au cours du match Science \& Motrice 1989; 8: 13-7.

[37] Viitasalo J, Rahkila, P, Österback L, Alén M. Vertical jumping height and horizontal overhead throwing velocity in young male athletes. J Sports Sci 1992; 10: 401-13.

[38] Freeston J, Ferdinands R, Rooney K. Throwing velocity and accuracy in elite end sub-elite cricket players: A descriptive study. Eur J Sport Sci 2007; 7(4): 231-7. 